\title{
Some temporal factors affecting conditional discrimination
}

\author{
LEE D. COOPER \\ University of North Carolina at Greensboro, Greensboro, North Carolina
}

\begin{abstract}
Pigeons acquired a serial conditional discrimination in which the onset of one of two colors (the instructional cue) on the center key preceded the onset of a white light (the trial cue) on one of two side keys. An autoshaping preparation was employed, in which food was delivered depending upon the color-side combination. Five groups of birds were studied at instructional cue durations of either 30 or $60 \mathrm{sec}$, and trial cue durations of 3, 6, or 12 sec. These temporal parameters allowed for different ratios of the instructional stimulus duration (I) to the trial stimulus duration (T), while keeping the absolute duration of the instructional stimulus constant, and for different absolute durations of the instructional stimulus, while keeping the I/T ratio constant. These manipulations were studied with either a 30 or a 60 -sec cycle (the interval between the onset of the intertrial interval and the offset of the trial cue), thus permitting examination of the cycle duration to trial duration ratios as well. The results showed that the larger the value of $I$ relative to that of $T$, the greater the final level of accuracy; this implicates the $I / T$ ratio as a controlling variable. In contrast, the larger the cycle duration $(C)$ relative to $T$, the greater the rate of responding to the trial stimulus, which is consistent with previous findings in autoshaping studies. These results suggest that whereas the $\mathrm{C} / \mathrm{T}$ ratio directly influences response rate, the $\mathrm{I} / \mathrm{T}$ ratio affects accuracy in a serial conditional discrimination.
\end{abstract}

The term conditional discrimination refers to behavior in which reinforcement in the presence of one stimulus is conditional upon other stimuli that are present (Heinemann \& Chase, 1970; Thomas, 1985). This behavior has been studied extensively in pigeons within a response-dependent paradigm involving both serial (Cumming, Berryman, \& Cohen, 1965) and simultaneous (Cumming \& Berryman, 1961) stimulus compounds. In the serial situation (Cumming et al., 1965), an instructional stimulus is presented prior to the onset of two trial stimuli. Reinforcement of a pecking response to a particular trial stimulus is conditional upon which instructional stimulus has been presented. Conditional discrimination in pigeons has also been demonstrated within a responseindependent, or autoshaping, paradigm (Looney, Cohen, Brady, \& Cohen, 1977; Williams, 1982, 1984). In the autoshaping paradigm, certain stimulus combinations (e.g., red-line and blue-circle) are followed by food, but

\footnotetext{
This paper is dedicated to the memory of Aaron J. Brownstein.

This study represents a major part of the author's doctoral dissertation, submitted to the University of North Carolina at Greensboro. Members of the dissertation committee were G. Rosenkrantz, P. S. Lawrence, S. Keane, and T. J. Johnston, with Richard Shull serving as chairperson. The author is especially grateful to Richard Shull, John Gibbon, and Peter Balsam for their advice and encouragement. Thanks to Russell Church and two anonymous reviewers for their perceptive comments. I also thank Frank Russell for his help in running subjects. The manuscript was prepared while the author was the recipient of a $\mathrm{Na}$ tional Research Service Award (NRSA) Postdoctoral Fellowship, MH18264 , at the New York State Psychiatric Institute and Columbia University. Requests for reprints and correspondence should be sent to Lee D. Cooper, now at the New York State Psychiatric Institute, 722 W. 168th Street, Box 40, New York, NY 10032.
}

other combinations (e.g., red-circle and blue-line) are not. Over the course of training, pigeons demonstrate a conditional discrimination by directing the majority of their pecking to the stimulus combinations that are followed by food. While certain properties of stimuli (e.g., stimulus similarity; see Carter \& Eckerman, 1975; Maki, Riley, \& Leith, 1976) have been studied for their effect on conditional control, temporal properties have not been studied as much.

The importance of the temporal structure of events is well known with regard to simple delay conditioningconsider, for example, the superiority of "spaced" over "'massed" training (Gormezano \& Moore, 1969). Both the speed of acquisition of autoshaped pecking and the rate of maintained pecking are directly related to the length of the intertrial interval (Cooper \& Brownstein, 1985; Gibbon, Baldock, Locurto, Gold, \& Terrace, 1977; Gibbon, Farrell, Locurto, Duncan, \& Terrace, 1980; Terrace, Gibbon, Farrell, \& Baldock, 1975). Furthermore, Gibbon et al. (1977) found that the number of trials to acquisition in autoshaping was inversely related to the ratio of the intertrial interval to the trial duration. Gibbon and Balsam (1981) proposed a model of autoshaping based on scalar expectancy theory (SET: Gibbon, 1977), in which they suggested that conditioning to a trial stimulus depends on the ratio of the delay of reinforcement in the trial relative to the delay of reinforcement in the situation as a whole. According to their formulation, the critical temporal property of the environment can be characterized as the ratio of the duration of the cycle between reinforcements (C) to the trial duration (T). 
Although the $\mathrm{C} / \mathrm{T}$ ratio is a critical variable for the acquisition and rate of conditioned responding within a nondifferential autoshaping procedure, its possible role in a serial conditional discrimination has not been studied. In a serial conditional discrimination, a stimulus may be a poor predictor of food when compared to other stimuli in the situation, yet it can still accurately predict when another stimulus will be followed by food. That is, given that the instructional stimulus precedes the trial stimulus, the instructional stimulus will predict food less than the trial stimulus will, because its onset is prior to the onset of the trial stimulus. But the instructional stimulus may nevertheless be a good predictor of which trial stimulus will occasion reinforcement. The issue studied here is how the temporal durations of these stimuli (cycle, trial, and instructional) interact to determine the formation and strength of a conditional discrimination.

Several studies have suggested an influence of temporal factors in serial conditional discrimination performance. Some of these studies have involved a "delayed" conditional discrimination. In this procedure, delay intervals are interposed between the offset of the instructional stimulus and the presentation of trial stimuli (Blough, 1959). The formation and strength of a conditional discrimination in these studies are often measured in terms of accuracy-the combined probability of correct responses in the presence of each instructional stimulus. Several researchers (e.g., Grant, 1975; Maki, Moe, \& Bierley, 1977; Roberts \& Kraemer, 1982; see also Holt \& Shafer, 1973) have shown that accuracy increases directly with the length of time between successive presentations of the instructional stimulus, or the interinstructional interval. These results suggest that the ratio of the interinstructional interval to the instructional stimulus interval may be critical and thus may be analogous to the C/T ratio effect in autoshaping (see Roberts \& Kraemer, 1984).

Williams (1982) studied the formation of a serial conditional discrimination in pigeons with an autoshaping procedure in which the trial stimulus (a line or circle) of a combination (green-line or red-circle) was presented for the last $5 \mathrm{sec}$ of a 30-sec cycle. He found that when the color, or instructional, stimulus of each combination (green or red) was presented throughout the 30 -sec cycle, the subjects' accuracy failed to rise above chance. Williams' (1982) suggestion, adapted from Gibbon and Balsams' (1981) model, was that the presentation of the instructional stimulus throughout the cycle results in that stimulus' becoming a poor predictor of food. The subjects did not "attend" to the instructional stimuli because these stimuli did not predict food: the stimuli could not function as conditional cues.

The results discussed above suggest that the temporal relation between $\mathrm{C}$ and the instructional stimulus duration (I) must be favorable enough (i.e., the $\mathrm{C} / \mathrm{I}$ ratio must be greater than some threshold) to engender responding, in order for a conditional discrimination to emerge. To test this possibility, a preliminary study on conditional discrimination in pigeons was conducted, using an autoshaping preparation. The instructional stimulus, which was either a blue or a red keylight on the center key of a threekey chamber, was presented throughout a 60 -sec cycle. The trial stimulus was a 6-sec white light on either the left or right key. Blue-left and red-right were followed by food, whereas blue-right and red-left were not. Thus, whether a particular position (i.e., left or right) of the white stimulus was followed by food was conditional upon the presence of either a blue or a red center key. Of particular interest, the durations of the cycle and the instructional stimulus were twice as long as in Williams' (1982) study. However, the $\mathrm{C} / \mathrm{I}$ ratio was the same, because the instructional stimulus was presented throughout the entire cycle. All birds in the preliminary study acquired a conditional discrimination. This result was surprising, because presenting the instructional stimulus for the entire cycle did not prevent a conditional discrimination. This result suggests that the formation and accuracy of a conditional discrimination is not invariantly related to the instructional stimulus duration, relative to the cycle duration.

The results in Williams (1982) and the results of our preliminary study suggest several possible controlling variables for accuracy in a serial conditional discrimination. One is the ratio of $I$ to the trial stimulus duration (T), or the I/T ratio. Analyzing the above results with respect to this ratio, we will see that the subjects in the preliminary work were exposed to a more favorable $\mathrm{I} / \mathrm{T}$ ratio $(I / T=60 / 6=10)$ than were the birds in Williams' (1982) study $(I / T=30 / 6=5)$. It should be noted that for the above results the $I / T$ ratio was equal to the $C / T$ ratio, for the instructional stimulus was presented throughout the cycle. If the I/T ratio is critical to accuracy, then it becomes important to examine the role of the $\mathrm{C} / \mathrm{T}$ ratio. Perhaps the $\mathrm{C} / \mathrm{T}$ ratio affects the response rate (Gibbon et al., 1977; Perkins et al., 1975).

A second possible controlling factor may be the absolute duration of instructional stimuli. Without an interstimulus interval, the instructional stimulus may have to be of long duration in order to provide enough information about the upcoming trial stimuli. Roberts and Grant (1974), for example, found accuracy increased in a delayed conditional discrimination task with increases in instructional stimulus duration. Whether accuracy in a conditional discrimination is based on the relative or absolute duration of stimulus events is thus unclear.

In the experiment reported here, these temporal variables were examined in a serial conditional discrimination. The design employed temporal parameters that allowed different I/T ratios, keeping the absolute duration of the instructional stimulus constant; and different absolute durations of the instructional stimulus, keeping the I/T ratio constant. These manipulations were studied with two cycle durations, permitting examination of the influence of the cycle duration to trial duration ratio on response rate and accuracy level. 


\section{METHOD}

\section{Subjects and Apparatus}

The subjects were 20 experimentally naive White Carneaux pigeons. The pigeons were maintained at approximately $80 \%$ of their free-feeding weights. Throughout the study, they had continuous access to water and grit in their separate home cages.

Four three-key conditioning chambers were used. Two chambers were made from modified ice chests with internal dimensions of $21 \times 27 \times 31 \mathrm{~cm}$. The three transulcent response keys, which were mounted $21 \mathrm{~cm}$ above the floor and $8 \mathrm{~cm}$ apart, could be transilluminated with different colors. A third chamber was $30 \times 35.5 \times 33.5 \mathrm{~cm}$, with three translucent response keys mounted $24 \mathrm{~cm}$ above the floor and $5 \mathrm{~cm}$ apart. A fourth chamber was $52 \times 38 \times 38 \mathrm{~cm}$, with three translucent response keys mounted $27.5 \mathrm{~cm}$ above the floor and $8 \mathrm{~cm}$ apart.

The following specifications were met by all chambers. A peck of at least $.2 \mathrm{~N}$ was required to interrupt an electrical contact that operated the recording circuits. An overhead houselight located on the ceiling near the front wall provided low-level general illumination. The houselight remained on at all times during the session except during feeder operation. Centered below the keys, $10 \mathrm{~cm}$ above the floor, was a $2 \times 2$ in. rectangular opening that gave access to mixed grain when the food hopper was raised. At such times, the feeder opening was illuminated but the keylights and houselight were darkened. An externally mounted fan provided masking noise and ventilation.

For two experimental chambers, the experimental manipulations and data collection were performed by electromechanical control and recording circuits in an adjoining room. For the other two experimental chambers, the experimental manipulations and data collection were controlled by a computer system (Walter \& Palya, 1984).

\section{Procedure}

Magaxine training. All the subjects were trained to eat from the grain hopper on the first day of training. When the bird was placed in the chamber, the hopper was lowered and raised repeatedly until the bird began eating quickly after the hopper was presented. Throughout this first session, none of the response keys was illuminated.

Conditional discrimination training. The autoshaping procedure, with the conditional discrimination imposed from the first session, began on the 2 nd day of training and lasted for 18 sessions. In this serial conditional discrimination procedure, the onset of the instructional stimulus preceded the onset of the trial stimulus, but

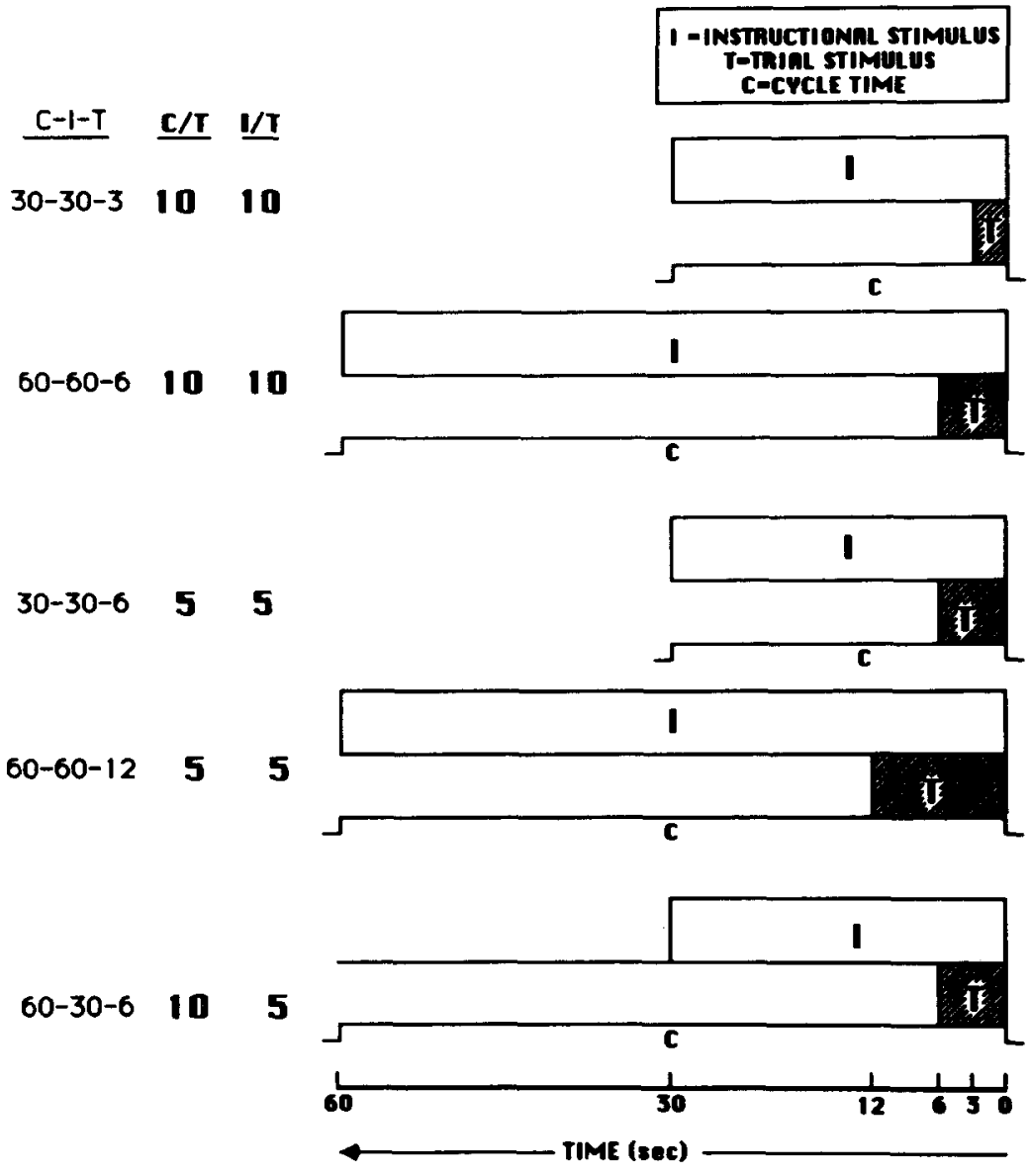

Figure 1. Experimental design of the five groups. The top portion of each panel represents the instructional stimulus duration (I). The bottom portion of each panel represents the trial stimulus duration ( $T$ ). The time between the onset of the intertrial interval and the offset of the trial is the cycle (C). Groups are designated by three hyphenated numbers, which gives values for $C$, I, and T. Groups are also designated by their $\mathrm{C} / \mathrm{T}$ and $\mathrm{IT}$ ratios. Duration values are indicated by the bottom time line. 
both stimuli terminated at the same time. Food was programmed, independent of responding, to follow certain instructional-trial stimulus combinations. A reinforced combination was followed by a 3-sec access to the grain hopper, and a nonreinforced combination was followed by the keys' being darkened for $3 \mathrm{sec}$.

The subjects were randomly assigned to one of five groups, in terms of the temporal parameters. In Figure 1, the temporal arrangements of the five experimental conditions are diagrammed. The temporal parameters of the experimental groups will be identified throughout the rest of this paper in either of two ways: (1) by three hyphenated numbers that correspond to the cycle duration (C), instructional stimulus duration (I), and trial stimulus duration (T), respectively (noted that $\mathrm{C}$ refers to the interval between the onset of the intertrial interval and the offset of the trial stimulus); (2) by identification according to each group's I/T ratio, such that a group is either a "high" $\mathrm{I} / \mathrm{T}$ ratio group or a "low" $\mathrm{I} / \mathrm{T}$ ratio group. In order to provide a replication of Williams' (1982) study and my own earlier pilot work, temporal parameter values similar to those used in those studies were employed.

(1) Group 30-30-3: The instructional stimulus was illuminated for the entire 30 -sec cycle and the trial stimulus was illuminated for the last $3 \sec$ of the cycle $(I / T=30 / 3=10, C / T=30 / 3=10)$.

(2) Group 60-60-6: The instructional stimulus was presented for the entire 60 -sec cycle and the trial stimulus was presented for the last $6 \mathrm{sec}$ of the cycle $(\mathrm{I} / \mathrm{T}=60 / 6=10, \mathrm{C} / \mathrm{T}=60 / 6=10)$. This group was a direct replication of the preliminary study. These two groups, Groups 30-30-3 and 60-60-6, constituted the high I/T ratio groups.

(3) Group 30-30-6: The instructional stimulus was presented for the entire 30-sec cycle and the trial stimulus was presented for the last $6 \mathrm{sec}$ of the cycle $(\mathrm{I} / \mathrm{T}=30 / 6=5, \mathrm{C} / \mathrm{T}=30 / 6=5)$. The temporal parameters of this group replicated those of Williams (1982).

(4) Group 60-60-12: The instructional stimulus was presented during the entire $60-\mathrm{sec}$ cycle and the trial stimulus was presented during the last $12 \mathrm{sec}$ of the cycle $(\mathrm{I} / \mathrm{T}=60 / 12=5, \mathrm{C} / \mathrm{T}=60 / 12=5)$. These two groups, Groups 30-30-6 and 60-60-12, represented the low I/T ratio groups.

(5) Group 60-30-6: The instructional stimulus was presented during the last $30 \mathrm{sec}$ of a $60-\mathrm{sec}$ cycle and the trial stimulus was presented for the last $6 \mathrm{sec}$ of the cycle $(\mathrm{I} / \mathrm{T}=30 / 6=5, \mathrm{C} / \mathrm{T}=$ $60 / 6=10$ ). Note that in first four groups the $I / T$ ratio was equal to the C/T ratio. Group 60-30-6 was the low $\mathrm{I} / \mathrm{T}$ control, because it has an I/T ratio equal to that of the low I/T groups and a $C / T$ ratio equal to that of the high $\mathrm{I} / \mathrm{T}$ ratio groups. Also, the first four groups were not exposed to an interinstructional interval, whereas this group has an interinstructional interval of $30 \mathrm{sec}$

There were 4 subjects in each group. The reinforced stimulus combinations and temporal parameters for each bird are listed in Table 1. The following notation system is used to describe the stimulus combinations in the conditional discrimination procedure: Color refers to which instructional stimulus was presented on the center key, whereas position refers to which side key the white trial stimulus was presented on. A stimulus combination designated as red-left signifies a combination with a red keylight (the instructional stimulus) presented on the center key and a white keylight (the trial stimulus) presented on the left side key. Reinforced and nonreinforced stimulus combinations were counterbalanced across birds within a group. Stimulus compound types were randomly presented, with the restriction that the same stimulus combination appear no more than three consecutive times. Food was therefore presented at random intervals, depending on the occurrence of a reinforced combination. Sessions consisting of $\mathbf{3 0}$ presentations of each stimulus compound; a total of 120 stimulus compounds was presented daily.
The comparisons of particular interest with respect to the strength of a conditional discrimination involved the low $I / T$ groups (Groups 30-30-6 and 60-60-12) versus the high I/T groups (Groups 30-30-3 and 60-60-6), in order to see whether I relative to $T$ was critical; and Groups $60-60-6$ and $60-60-12$ versus Groups 30-30-3 and 30-30-6, to see whether absolute I was critical.

Finally, if the $\mathrm{I} / \mathrm{T}$ ratio is important for accuracy, then it was of particular concern to compare groups across $\mathrm{C} / \mathrm{T}$ ratios to see its influence on the rate of responding. That is, if the high I/T groups (Groups 60-60-6 and 30-30-3) had the better accuracy, did the high $\mathrm{C} / \mathrm{T}$ groups (Groups 60-60-6, 30-30-3, and 60-30-6) have higher response rates than the low $\mathrm{C} / \mathrm{T}$ groups (Groups 60-60-12 and 30-30-6)?

Reversal condition. In order to assess the potency of the $\mathrm{I} / \mathrm{T}$ ratio for the strength of a conditional discrimination, the $\mathrm{I} / \mathrm{T}$ ratios for Groups 30-30-3 and 30-30-6 as well as Groups 60-60-6 and 6060-12 were reversed by changing Ts: Group 30-30-3 had the trial stimulus illuminated for the last $6 \mathrm{sec}$ of the cycle, and Group 30$30-6$ had the trial stimulus illuminated for the last $3 \mathrm{sec}$ of the cycle; similarly, Group 60-60-6 had the trial stimulus illuminated for the last $12 \mathrm{sec}$ of the cycle, and Group 60-60-12 had the trial stimulus illuminated for the last $6 \mathrm{sec}$ of the cycle. Hence, Groups 30-30-6 and 60-60-12, which had I/T ratios of 5 in the initial training phase, now had I/T ratios of 10 , and Groups 30-30-3 and 60-60-6, which had $I / T$ ratios of 10 in the initial phase, now had $I / T$ ratios of 5 . Training on these conditions continued for 10 additional sessions.

Response measure. The principal response measure of accuracy for this experiment was a discrimination index (DI). DIs for each session were calculated in two steps. First, a proportion correct for each instructional stimulus was computed, by dividing pecks on all keys during the reinforced stimulus combinations by the total pecks on all keys during all combinations with that instructional stimulus. For example, the proportion correct for the red instruc-

Table 1

Temporal Parameters and Reinforced Stimulus Combinations for Individual Birds

\begin{tabular}{|c|c|c|c|c|}
\hline Bird & $\mathbf{C}$ & I & $\mathbf{T}$ & $\begin{array}{c}\text { Reinforced } \\
\text { Stimulus Combinations } \\
\text { (Instructional-Trial) }\end{array}$ \\
\hline 1 & 30 & 30 & 3 & red-left, blue-right \\
\hline 2 & 30 & 30 & 3 & red-right, blue-left \\
\hline 3 & 30 & 30 & 3 & red-left, blue-right \\
\hline 4 & 30 & 30 & 3 & red-right, blue-left \\
\hline 5 & 60 & 60 & 6 & red-left, blue-right \\
\hline 6 & 60 & 60 & 6 & red-right, blue-left \\
\hline 7 & 60 & 60 & 6 & red-left, blue-right \\
\hline 8 & 60 & 60 & 6 & red-right, blue-left \\
\hline 9 & 30 & 30 & 6 & red-left, blue-right \\
\hline 10 & 30 & 30 & 6 & red-right, blue-left \\
\hline 11 & 30 & 30 & 6 & red-left, blue-right \\
\hline 12 & 30 & 30 & 6 & red-right, blue-left \\
\hline 13 & 60 & 60 & 12 & red-left, blue-right \\
\hline 14 & 60 & 60 & 12 & red-right, blue-left \\
\hline 15 & 60 & 60 & 12 & red-left, blue-right \\
\hline 16 & 60 & 60 & 12 & red-right, blue-left \\
\hline 17 & 60 & 30 & 6 & red-left, blue-right \\
\hline 18 & 60 & 30 & 6 & red-right, blue-left \\
\hline 19 & 60 & 30 & 6 & red-left, blue-right \\
\hline 20 & 60 & 30 & 6 & red-right, blue-left \\
\hline
\end{tabular}

Note- $\mathrm{C}=$ cycle duration, $\mathrm{I}=$ instructional stimulus duration, $\mathrm{T}=$ trial stimulus duration (in seconds). 
tional stimulus was computed by dividing red-left pecks, a reinforced combination of the red stimulus on the center key and the white stimulus on the left key, by the total pecks during all combinations involving the red stimulus: red-left/(red-left + red-right) $=$ red DI. Then the overall DI was obtained as the average of the proportion for the two instructional stimuli. The DI measures the overall strength of conditional stimulus control. If responding was independent of any instructional control, overall performance would be at .50 . When DI $>.50$, the response rate in reinforced stimulus combinations is higher than in the nonreinforced stimulus combinations.

Two out of the 20 pigeons (Birds 13 and 17) were not included in the following analyses, because of their near zero response rates to some, or all, stimulus compounds. The exclusion of the data from these 2 subjects produced smaller differences among the groups, and thus provided a conservative comparison among them.

\section{RESULTS}

Figure 2 shows the mean DI, or accuracy, for each group as a function of experimental session. All groups exhibited a DI at or above $70 \%$ by the 12 th day of training. Two groups, Groups 30-30-3 and 60-60-6, showed a gradual rise from chance performance to a level of $90 \%$ discrimination by the end of the 18 training sessions. The other three groups, Groups 30-30-6, 60-60-12, and 60$30-6$, appeared to asymptote at lower levels.

The two groups exposed to the high $\mathrm{I} / \mathrm{T}$ ratio achieved the higher asymptote. This finding is especially strengthened by the performance of Group 60-30-6. This group had an I/T ratio of 5 and a $C / T$ ratio of 10 , yet it achieved an aymptotic DI comparable to that for the other low $\mathrm{I} / \mathrm{T}$ groups.
An examination of the individual DIs within each group also supports the observation that the high $\mathrm{I} / \mathrm{T}$ ratio resulted in a higher level of differential control. DIs summed over the last 3 days of discrimination training for each subject are listed in Table 2, along with each bird's $C / T$ and $I / T$ ratio. For the high $I / T$ groups (Groups 30-30-3 and 60-60-6), 6 out of 8 birds reached DIs close to or above $85 \%$. Only 3 out of 7 birds in the low I/T groups (Groups 30-30-6 and 60-60-12) were close to $85 \%$ accuracy, and in the low I/T group (Group 60 30-6, the control), only 1 bird exhibited discrimination performance above $85 \%$.

These results show that a critical determinant in the accuracy level achieved by pigeons in a conditional discrimination is the relative duration of the stimulus elements. Evidently the $\mathrm{I} / \mathrm{T}$ ratio, not the $\mathrm{C} / \mathrm{T}$ ratio, is the primary influence on the final discrimination level of a conditional discrimination.

These observations were confirmed statistically by planned comparisons. The mean DIs from the last 3 days of training for each group were entered into a set of five planned comparisons. The discrimination indices of the two low I/T groups did not differ significantly from each other $[F(1,10)=.039, p>.25]$; neither did those of the two high $\mathrm{I} / \mathrm{T}$ groups $[F(1,10)=.21, p>.25]$. Thus the absolute duration of the instructional stimulus or the trial stimulus were not factors in acquisition. However, the combined DIs for the high I/T groups were significantly higher than the combined DIs for the low I/T groups $[F(1,10)=9.07, p<.025]$, confirming the critical role of the $1 / T$ ratio. Also, the combined DIs of the low I/T

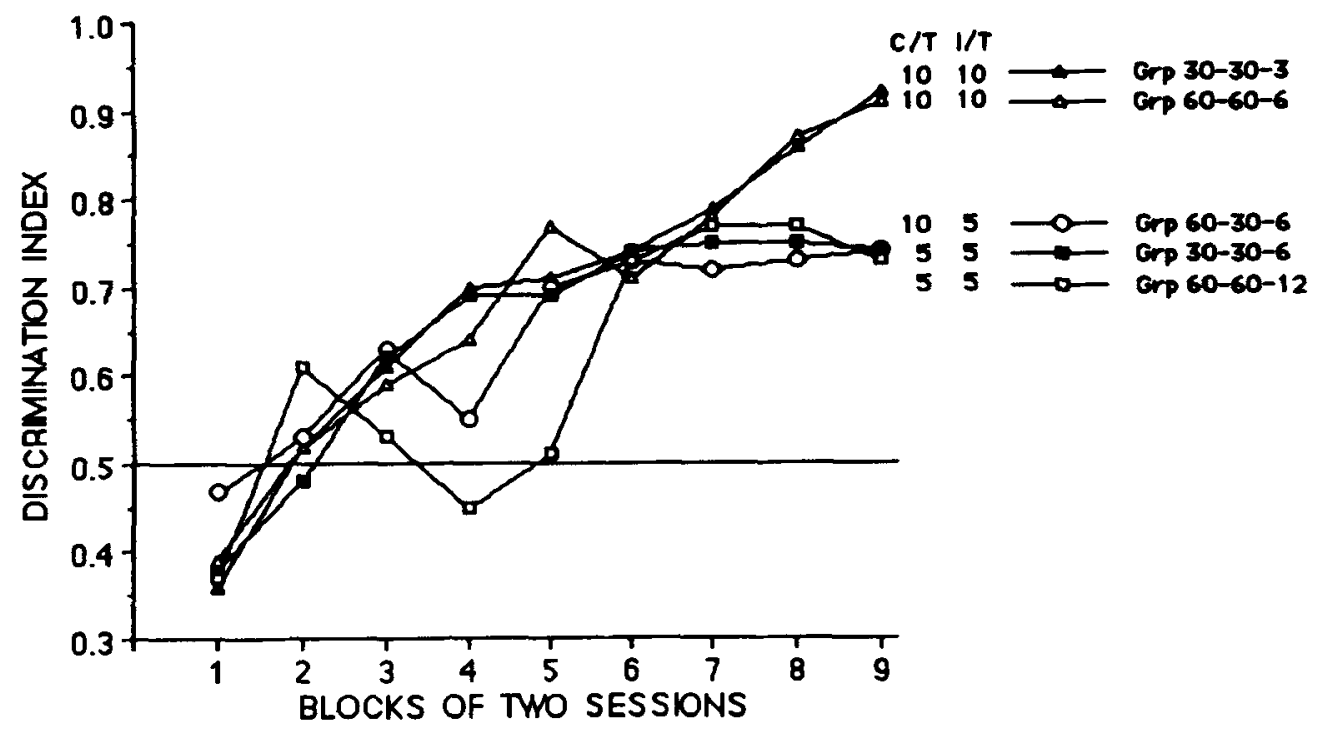

Figure 2. Combined proportion of total pecks in response to reinforced stimulus combinations during conditional discrimination training. 
Table 2

Accuracy Data for Individual Subjects

\begin{tabular}{ccccc}
\hline Group (C-I-T) & Bird & C/T Ratio & I/T Ratio & DI \\
\hline $30-30-3$ & 1 & 10 & 10 & .80 \\
$30-30-3$ & 2 & 10 & 10 & .96 \\
$30-30-3$ & 3 & 10 & 10 & .87 \\
$30-30-3$ & 4 & 10 & 10 & .99 \\
$60-60-6$ & 5 & 10 & 10 & .90 \\
$60-60-6$ & 6 & 10 & 10 & .78 \\
$60-60-6$ & 7 & 10 & 10 & .88 \\
$60-60-6$ & 8 & 10 & 10 & .98 \\
$30-30-6$ & 9 & 5 & 5 & .58 \\
$30-30-6$ & 10 & 5 & 5 & .84 \\
$30-30-6$ & 11 & 5 & 5 & .69 \\
$30-30-6$ & 12 & 5 & 5 & .88 \\
$60-60-12$ & 14 & 5 & 5 & .72 \\
$60-60-12$ & 15 & 5 & 5 & .59 \\
$60-60-12$ & 16 & 5 & 5 & .90 \\
$60-30-6$ & 18 & 5 & 10 & .51 \\
$60-30-6$ & 19 & 5 & 10 & .75 \\
$60-30-6$ & 20 & 5 & 10 & .99 \\
\hline
\end{tabular}

Note-C = cycle duration, $\mathrm{I}=$ instructional stimulus duration, $\mathrm{T}=$ trial stimulus duration (in seconds); DI = discrimination index (percent correct).

groups did not differ significantly from the DI of the low I/T control group, Group 60-30-6 $[F(1,10)=.035$, $p>.25$ ], whereas the combined DIs for the high $\mathrm{I} / \mathrm{T}$ groups did differ from the DI for this group $[F(1,10)=$ $5.16, p<.05]$. This demonstrates that the $\mathrm{C} / \mathrm{T}$ ratio was not the critical factor in the final level of accuracy.

Figure 3 shows the mean DIs for four groups that had reversed Ts. In the reversal phase the $T$ for the high $I / T$ ratio groups was lengthened and that of the low $\mathrm{I} / \mathrm{T}$ ratio groups was shortened. When the subjects in the high I/T ratio groups were switched to a low $\mathrm{I} / \mathrm{T}$ ratio, a transient disruption in the DI occurred between Sessions 20-24, followed by recovery to the previous high levels. Thus, changing to a lower I/T did not permanently retard the discrimination once it had been established.

For the subjects in the low I/T ratio groups, changing to the higher $\mathrm{I} / \mathrm{T}$ ratio produced a noticeable change in discrimination, which continued to improve over the 10 sessions of training until it reached a level near that of the high I/T groups. This shows that the effect of the low I/T ratio on conditional discrimination was not permanent.

In sum, the acquisition data showed conditional discriminations under all conditions. All groups reached final levels of discrimination of greater than $70 \%$. However, both the acquisition and reversal data showed that the final levels of performance were influenced by the I/T ratio, and not by the $\mathrm{C} / \mathrm{T}$ ratio.

The following analyses examined the influence of the $\mathrm{C} / \mathrm{T}$ ratio on the eliciting power of stimuli in a conditional discrimination. For Figure 4, the groups in this study were collapsed across $\mathrm{C} / \mathrm{T}$ ratios. The high $\mathrm{C} / \mathrm{T}$ group $(\mathrm{C} / \mathrm{T}=10)$ consisted of birds in Groups 30-30-3, 60-60-6, and 60-30-6; the low $\mathrm{C} / \mathrm{T}$ group $(\mathrm{C} / \mathrm{T}=5)$ consisted of birds in Groups 30-30-6 and 60-60-12. Figure 4 (upper panel) shows the mean DI as a function of $\mathrm{C} / \mathrm{T}$ ratio across training sessions. This figure shows no effect of $\mathrm{C} / \mathrm{T}$ ratio on accuracy early in training, but a slight effect late in training. An overall ANOVA, based on DIs in the first and last five sessions, showed a significant main effect of exposure for the first five days as opposed to the last five days $[F(1,176)=130.8, p<.0001]$, with no significant difference associated with $\mathrm{C} / \mathrm{T}$ ratio $(F<1)$ or $\mathrm{C} / \mathrm{T} \times$ exposure interaction $(F<1)$. This analysis again confirms that the $C / T$ ratio was not the crucial factor in discriminative performance.

Figure 4 (lower panel) shows mean rates of response

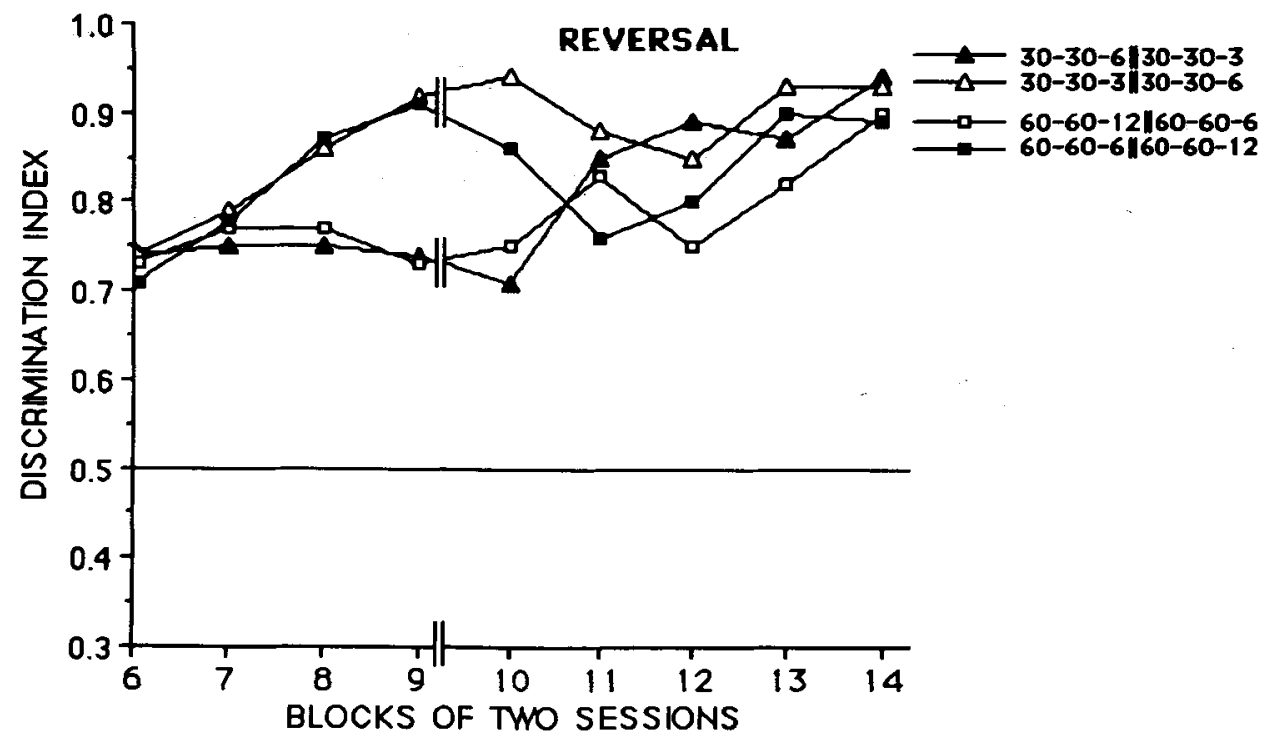

Figure 3. Combined proportion of total pecks in response to reinforced stimulus combinations during the last 6 sessions of conditional discrimination training and 10 sessions of the reversal condition. In the reversal condition, Groups 30-30-3 and 30-30-6 had $T$ (trial stimulus durations) reversed, as did Groups 60-60-6 and 60-60-12. 
to reinforced stimulus combinations as a function of $\mathrm{C} / \mathrm{T}$ ratio. In contrast to the upper panel, this one shows a large difference in response rates early in training, with a smaller difference late in training. An overall ANOVA on response rates, based on the first and last five sessions, showed significant main effects of high $\mathrm{C} / \mathrm{T}$ ratio as opposed to low $\mathrm{C} / \mathrm{T}$ ratio $[F(1,176)=5.5, p<.02]$ and of exposure $[F(1,176)=21.7, p<.0001]$. There was a significant $C / T \times$ exposure interaction $[F(1,176)=$ $5.01, p<.026]$. Further post hoc comparisons showed that response rates for the high $\mathrm{C} / \mathrm{T}$ group were significantly greater than for the low $\mathrm{C} / \mathrm{T}$ group during the first 5 days $[F(1,88)=11.02, p<.01]$, while response rates did not differ among groups during the last 5 days $(F<1)$. These data suggest that the $\mathrm{C} / \mathrm{T}$ ratio influences the strength of responding in a conditional discrimination, an effect similar to its well-documented role in nondifferential autoshaping.

Figure 5 shows the mean percent of total pecks on the instructional and trial keys, averaged over the last 3 days of discrimination training (response location data for individual subjects are presented in the last two columns in Table 3). Groups were collapsed according to $I / T$ ratio to see whether the I/T ratio affected response location. Figure 5 shows that for both groups, responding occurred with respect to the trial key, rather than the instructional key. Visual observation of the data reveal a preference for the trial stimuli throughout the course of training. For each subject, the rate of response to the instructional stimulus prior to presentation of the stimulus compound is listed in column 3. The individual data show that most subjects responded very little, if at all, to the instructional stimulus during its pretrial presentation. The majority of the subjects' responding occurred during the period in which the instructional stimulus and the trial stimulus were both illuminated. These findings show that although instructional stimuli did exert conditional control over pecking, they did not directly evoke responding.

\section{DISCUSSION}

In the present experiment, the formation of a conditional discrimination by pigeons occurred under all duration values for the instructional stimulus. Thus, the present
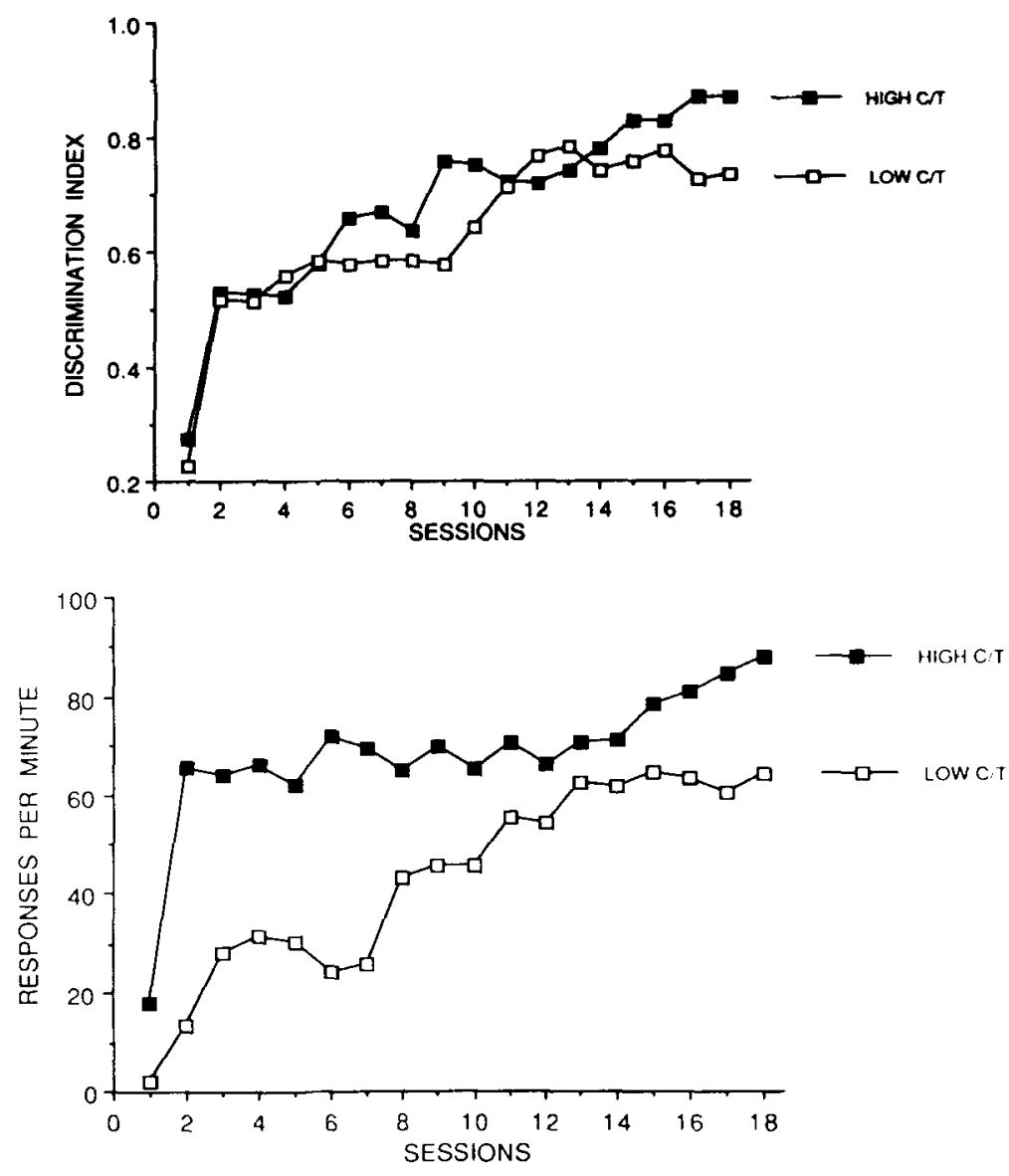

Figure 4. Upper panel: mean discrimination index as a function of cycle duration/trial stimulus duration (C/T) ratio across conditional training. Lower panel: mean response rates as a function of $\mathrm{C} / \mathrm{T}$ ratio across conditional discrimination training. Groups are collapsed across $C / T$ ratios. Groups 30-30-3, 60-60-6, and 6030-6 represent the high $\mathrm{C} / \mathrm{T}$ group, and Groups 30-30-6 and 60-60-12 represent the low C/T group. 
INSTRUCTIONAL STIMULUS Z TRial stimulus

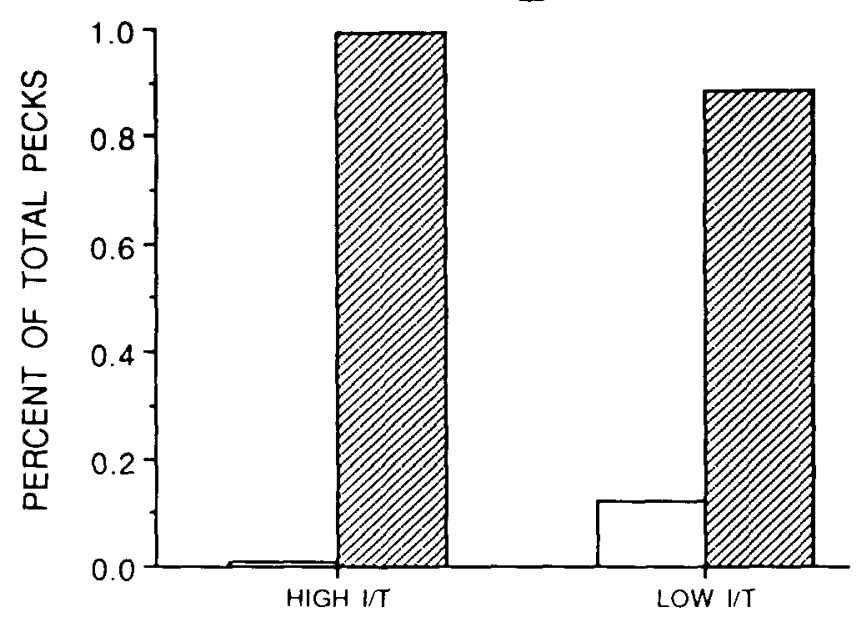

Figure 5. Percent of total pecks in response to the stimulus combinations, averaged over the last 3 days of conditional discrimination training. Groups are collapsed across instructional stimulus duration/trial stimulus duration (I/T) ratios. Groups 30-30-3 and 60-60-6 represent the high $\mathrm{I} / \mathrm{T}$ group, and Groups 30-30-6, 60-6012, and 60-30-6 represent the low I/T group.

findings fail to support Williams' (1982) observation that presenting the instructional stimulus throughout the cycle prevents the acquisition of a conditional discrimination. Williams' procedure was identical to that in the present study apart from the trial stimulus itself, which was either a white horizontal line or a white circle. Although it has been demonstrated that pigeons learn conditional discriminations more rapidly with hues than with lines or forms (Carter \& Eckerman, 1975), it is hard to see why such a procedural difference would account for the total lack of control by conditional stimuli in Williams' experiment.

The major finding in the present study was that certain features of the temporal arrangements did influence accuracy, while others did not. Although a conditional discrimination was demonstrated under all conditions, accuracy was affected by the instructional stimulus duration (I) relative to the trial stimulus duration $(\mathrm{T})$. The greater the $\mathrm{I} / \mathrm{T}$ ratio, the better the conditional discrimination achieved by pigeons. In contrast, the $\mathrm{C} / \mathrm{T}$ ratio controlled responding to the trial stimulus, a finding that is consonant with previous results on autoshaping (e.g., Perkins, et al., 1975). The groups exposed to the greater $C / T$ ratio had a higher response rate to the trial stimulus, but not necessarily a higher accuracy level.

A major difference between our results and those of most other studies on autoshaping involves the stimulus condition during the intertrial interval. The present study presented an explicit stimulus, namely the instructional cue, during all or most of the intertrial interval. It was apparent, however, that the $\mathrm{C} / \mathrm{T}$ ratio directly influenced the elicitation of responding. Thus, the strength of responding may be unaffected by the instructional stimulus in a conditional discrimination.

The observation that the I/T ratio controlled accuracy was further supported by the findings in the reversal condition. The original low I/T ratio groups that were exposed to a novel high $\mathrm{U} T \mathrm{~T}$ ratio improved their performance to a level equal to that for the original high $\mathrm{I} / \mathrm{T}$ ratio groups. When they were exposed to a new low I/T ratio, the original high $\mathrm{I} / \mathrm{T}$ ratio groups showed some initial disruption in their discriminative performance, with a subsequent return to their previous performance. Williams

Table 3

Response Location Data for Individual Subjects

\begin{tabular}{ccccc}
\hline & & $\begin{array}{c}\text { Percent of Total } \\
\text { Initial }\end{array}$ & $\begin{array}{c}\text { Pecks on } \\
\text { Instructional Key }\end{array}$ & $\begin{array}{c}\text { Percent of Total } \\
\text { Pecks on Trial Key }\end{array}$ \\
\hline $30-30-3$ & 1 & .18 & .00 & 1.00 \\
$30-30-3$ & 2 & .00 & .00 & 1.00 \\
$30-30-3$ & 3 & .00 & .00 & 1.00 \\
$30-30-3$ & 4 & .00 & .00 & 1.00 \\
$60-60-6$ & 5 & .01 & .00 & 1.00 \\
$60-60-6$ & 6 & .03 & .05 & .95 \\
$60-60-6$ & 7 & .00 & .01 & .99 \\
$60-60-6$ & 8 & .00 & .00 & 1.00 \\
$30-30-6$ & 9 & .15 & .00 & 1.00 \\
$30-30-6$ & 10 & 4.36 & .40 & .60 \\
$30-30-6$ & 11 & .71 & .64 & .36 \\
$30-30-6$ & 12 & .34 & .02 & .98 \\
$60-60-12$ & 14 & 1.37 & .01 & .99 \\
$60-60-12$ & 15 & .03 & .01 & .99 \\
$60-60-12$ & 16 & .01 & .00 & .00 \\
$60-30-6$ & 18 & .25 & .04 & .96 \\
$60-30-6$ & 19 & .72 & .10 & .90 \\
$60-30-6$ & 20 & .01 & .01 & .99 \\
\hline
\end{tabular}

Note-C $=$ cycle duration, $\mathbf{I}=$ instructional stimulus duration, $\mathbf{T}=$ trial stimulus duration (in seconds); initial response rate is given in terms of responses per minute and signifies responses to the instructional stimulus prior to presentation of the stimulus compound. 
(1982) also ran a reversal condition after acquisition training: for one group, instructional stimuli were presented for the entire $30-\mathrm{sec}$ cycle, having previously been presented for only the last $5 \mathrm{sec}$ of the cycle: for another group, instructional stimuli were presented for the last 5 sec of the 30-sec cycle, having initially been presented for the entire cycle. Williams found a similar effect during the reversal condition. When the subjects in the reversal condition had the instructional stimuli on during the entire cycle, an initial transient disruption of the discrimination occurred, followed by recovery to the previous level. But the group that was presented with the instructional stimuli for only the last $5 \mathrm{sec}$ of the cycle showed an immediate improvement in discrimination performance. Additionally, Holt and Shafer (1973) found that within a simultaneous conditional discrimination procedure, increasing the interinstructional interval improved accuracy levels, whereas decreasing the interinstructional interval did not attenuate stable performance.

The serial presentation of stimuli in the present conditional discrimination experiment resulted in a majority of pecks on the side keys with very little pecking on the center key. This pattern of responding suggests that the center key exerted an instructional function (Carter \& Werner, 1978; Cumming \& Berryman, 1965; Holland, 1983; Honig, 1978), rather than a direct evoking function. That is, one stimulus "instructs" the animal to respond to another stimulus that actually evokes the response. The lack of pecking in response to the instructional stimulus does not mean of course that pigeons simply "ignored" it. If so, accuracy should have been at chance. An alternative account would be a stimulusconfiguration view, in which the stimulus combination evokes responding (Kehoe \& Gormezano, 1980). According to this view, responding to the trial key might reflect pecking on the most temporally predictive key within the stimulus configuration.

On a descriptive level, the results of the present study are consistent with the explanation that when one stimulus (S1) is presented prior to a second stimulus (S2), S2 evokes responding since it is more (temporally) predictive of food. The "instructional" function of S1 emerges when (1) $S 2$ is a better predictor of reinforcement than $S 1$, and (2) $S 1$ is in a conditional relation with the S2-reinforcement relationship. Thus, in the present experiment, the trial stimulus (S2) functioned as a stimulus that directly elicited responding, whereas the instructional stimulus (S1) functioned to strengthen the trial-reinforcer relation momentarily. Perhaps the strength of the instructional stimulus is directly related to the extent to which the trial stimulus is a better temporal predictor of reinforcement. In the present findings, differences among stimulus durations reflected in the $I / T$ ratios could have facilitated the instructional control of stimuli. That is, the higher the I/T ratio, the more the better predictor of food (the trial stimulus) was compared to the instructional stimulus, and thus the stronger the function of the instructional stimulus became.
It is clear, however, that the $\mathrm{I} / \mathrm{T}$ ratio cannot account for some features of conditional discrimination performance. Previous work on simultaneous conditional discriminations has produced quite high accuracy levels (e.g., Cumming \& Berryman, 1965; Williams, 1982). Thus, the $\mathrm{I} / \mathrm{T}$ ratio does not explain the strength of discriminative performance in a simultaneous condition, in which the $\mathrm{I} / \mathrm{T}$ ratio is low (I/T $=1$ ). It is possible that when the instructional and trial stimuli are presented simultaneously in a conditional discrimination, they may form a configurational cue that controls responding (Holland \& Block, 1983; Saavedra, 1975; Thomas, Stengel, Sherman, $\&$ Woodford, 1987). In the simultaneous case, then, the $\mathrm{C} / \mathrm{T}$ ratio may control accuracy.

Interestingly, the I/T ratio account would predict that the deleterious effects of increasing the delay interval in a delayed conditional discrimination task (Roberts, 1972) could be attenuated by increasing $I$ and/or decreasing $T$. Roberts increased $I$ by increasing the number of responses required to advance to the delay interval. His results showed that with the same delay interval, performance improved as I was lengthened. Previous work on conditional discrimination (e.g., Holt \& Shafer, 1973; Roberts, 1972; Roberts \& Grant, 1974; Roberts \& Kraemer, 1982) has shown that the length of the interinstructional interval and of I are important variables. Along with the present results, it seems that the temporal variables of the interinstructional interval, $I$, and $T$ may all interact with each other to influence accuracy in a serial conditional discrimination.

The present data show that the final level of accuracy of a conditional discrimination within an autoshaping paradigm is a function of the ratio of the instructional stimulus duration to trial stimulus duration (I/T). In accord with other studies in autoshaping (e.g., Perkins et al., $1975)$, the ratio of the cycle duration to trial duration $(C / T)$ has been shown to influence response rate. It has been proposed that the instructional control exerted by the instructional stimulus reflects the combined effect of its competition with the trial stimulus for direct control over responding and its conditional relationship with the trial stimulus-reinforcer relation. An inverse relation between competition with the trial stimulus and strength of instructional control has been suggested, with the $\mathrm{I} / \mathrm{T}$ ratio as an index of this relation. The $\mathrm{C} / \mathrm{T}$ ratio apparently has a more direct effect on the strength of the trial stimulus-reinforcer association, modulating the overall eliciting power of the trial stimulus.

\section{REFERENCES}

BLough, D. S. (1959). Delayed matching in the pigeon. Journal of the Experimental Analysis of Behavior, 2, 151-160.

Carter, D. E., Eckerman, D. A. (1975). Symbolic matching by pigeons: Rate of leaming complex discriminations predicted from simple discriminations. Science, 187, 662-664.

Carter, D. E., \& Werner, T. J. (1978). Complex learning and information processing by pigeons: A critical analysis. Journal of the Experimental Analysis of Behavior, 29, 565-601. 
COOPER, L. D., Brownstein, A. J. (1985). Immediacy of reinforcement in autoshaping with pigeons. Psychological Record, 35, 353-364.

Cumming, W. W., Berryman, R. (1961). Some data on matching behavior in the pigeon. Journal of the Experimental Analysis of Behavior, 4, 281-284.

Cumming, W. W., Berryman, R. (1965). The complex discriminated operant: Studies of matching-to-sample and related problems. In D. I. Mostofsky (Ed.), Stimulus generalization (pp. 284-330). Stanford, CA: Stanford University Press.

Cumming, W. W., Berryman, R., Cohen, L. (1965). Acquisition and transfer of zero-delay matching. Psychological Reports, 17, 435-445.

GibBoN, J. (1977). Scalar expectancy theory and Weber's law in animal timing. Psychological Review, 84, 279-325.

Gibbon, J., Baldock, M. D., Locurto, C. M., Gold, L., \&erRACE, H. S. (1977). Trial and intertrial durations in autoshaping. Journal of Experimental Psychology: Animal Behavior Processes, 3, 264-284.

Gibbon, J., Balsam, P. D. (1981). The spread of association in time. In C. M. Locurto, H. S. Terrace, \& J. G. Gibbon (Eds.), Autoshaping and conditioning theory (pp. 219-254). New York: Academic Press.

Gibbon, J., Farrell, L., Locurto, C. M., Duncan, H. J., * TerRACE, H. S. (1980). Partial reinforcement in autoshaping with pigeons. Animal Learning \& Behavior, 8, 45-59.

Gormezano, I., a Moore, J. W. (1969). Classical conditioning. In M. H. Marx (Ed.), Leaming: Processes (pp. 120-203). Toronto: Macmillan.

Grant, D. S. (1975). Proactive interference in pigeon short-term memory. Journal of Experimental Psychology: Animal Behavior Processes, 1, 207-220.

heinemann, E. G., Chase, S. (1970). Conditional stimulus control. Joumal of Experimental Psychology, 84, 187-197.

Holland, P. C. (1983). "Occasion-setting"' in conditional discriminations. In M. Commons, R. Hermstein, \& A. R. Wagner (Eds.), Harvard Symposium on the Quantitative Analysis of Behavior: Discrimination processes, Vol. IV (pp. 183-206). New York: Ballinger.

Holland, P. C., Block, H. (1983). Evidence for unique cue in positive patterning. Bulletin of the Psychonomic Society, 21, 297-300.

Holt, G. L., Shafer, J. N. (1973). Function of intertrial interval in matching-to-sample. Journal of the Experimental Analysis of Behavior, 19, 181-186.

HoNIG, W. K. (1978). Studies of working memory in the pigeon. In S. H. Hulse, H. Fowler, \& W. K. Honig (Eds.), Cognitive processes in animal behavior (pp. 211-248). Hillsdale, NI: Erlbaum.

Kehoe, E. J., \& Gormezano, I. (1980). Configuration and combination laws in conditioning with compound stimuli. Psychological Bulle$\operatorname{tin}, 87,351-378$

Looney, T. A., Cohen, L. R., Brady, J. H., \& Cohen, P. S. (1977). Conditional discrimination performance by pigeons on a response- independent procedure. Journal of the Experimental Analysis of Be havior, 27, 363-370.

Maki, W. S., MoE, J. C., Bierley, C. M. (1977). Short-term memory for stimuli, responses, and reinforcers. Joumal of Experimental Psychology: Animal Behavior Processes, 3, 156-177.

MAKI, W. S., JR., RILEY, D. A., LEITH, C. R. (1976). The role of test stimuli in matching to compound samples by pigeons. Animal Learning \& Behavior, 4, 13-21.

Perkins, C. C., Beavers, W. O., Hancock, R. A., Hemmendinger, P. C., Hemmendinger, D., \& Ricci, J. A. (1975). Some variables affecting rate of key pecking during response-independent procedures (autoshaping). Journal of the Experimental Analysis of Behavior, 24, 59-72.

RoberTs, W. A. (1972). Short-term memory in the pigeon: Effects of repetition and spacing. Joumal of Experimental Psychology, 94, 74-83.

Roberts, W. A., Grant, D. S. (1974). Short-term memory in the pigeon with presentation time precisely controlled. Learning \& Motivation, 5, 393-408.

Roberts, W. A. Kraemer, P. J. (1982). Some observations of the effects of intertrial interval and delay on delayed matching to sample in pigeons. Journal of Experimental Psychology: Animal Behavior Processes, 8, 342-353.

Roberts, W. A., \& Kraemer, P. J. (1984). Temporal variables in delayed matching to sample. In J. Gibbon \& L. G. Allan (Eds.), Timing and time perception (pp. 335-345). New York: New York Academy of Sciences.

SaAvedra, M. A. (1975). Pavlovian compound conditioning in the rabbit. Learning \& Motivation, 6, 314-326.

Terrace, H. S., Gibion, J., Farrell, L., a Baldock, M. D. (1975). Temporal factors influencing the acquisition and maintenance of an autoshaped keypeck. Animal Learning \& Behavior, 3, 53-62.

Thomas, D. R. (1985). Contextual stimulus control of operant responding in pigeons. In P. D. Balsam \& A. Tomie (Eds.), Context and leaming (pp. 295-321). Hillsdale, NJ: Erlbaum.

Thomas, D. R., Stengel, T., Sherman, L., \&oodford, M. (1987). Factors affecting conditional discrimination learning by pigeons. Journal of the Experimental Analysis of Behavior, 48, 277-287.

Walter, D. E., \& Palya, W. L. (1984). An inexpensive experiment controller for stand-alone applications or distributed processing networks. Behavior Research Methods, Instruments, \& Computers, 16, 125-134.

WILLIAMS, B. A. (1982). On the failure and facilitation of conditional discrimination. Journal of the Experimental Analysis of Behavior, 38, 265-280.

Williams, B. A. (1984). Relative stimulus validity in conditional discrimination. Animal Learning \& Behavior, 12, 117-121.

(Manuscript received May 6, 1988; revision accepted for publication August 3,1988 . 